\title{
PENGEMBANGAN DAYA TARIK WISATA BAKUKUNG CIANTEN MELALUI PERANCANGAN PETUNJUK ARAH BERBASIS MEDIA ONLINE
}

\author{
Fahmi Irfani ${ }^{1}$, Agung Derajat, Abdul Rosyid ${ }^{2}$ \\ fahmiirfani@fai.uika-bogor.ac.id \\ Dosen Fakultas Agama Islam ${ }^{1}$, Mahasiswa KKN Kelompok 60 Tahun $2018^{2}$
}

\begin{abstract}
ABSTRAK
Destinasi wisata yang ada di Indonesia sangatlah banyak namun permasalahannya adalah kurangnya pengelolaan dan informasi tentang tempat wisata tersebut, begitupula yang terjadi di tempat wisata Bukit Bakukung yang berada di antara perkebunan PTPN VIII Cianten dan Taman Nasional Gunung Halimun, walaupun sudah berbagai upaya yang dilakukan Masyarakat Cianten untuk mengenalkan Bukit Bakukung kepada khlayak ramai namun tetap belum bisa meramaikan pengunjung untuk datang ke Bukit Bakukung. Fluktuasi jumlah pengunjung itu berimbas terhadap pendapatan pedagang yang ada didalam tempat wisata dan pendapatan pengelola yang secara kolektif Bukit Bakukung ini di kelola oleh masyarakat Cianten. Oleh karena itu kami memberikan solusi untuk mengatasi masalah tersebut dengan cara Pengembangan Daya Tarik Wisata Bakukung Cianten Melalui Perancangan Petunjuk Arah Berbasis Media Online. Diharapkan dengan program pengembangan ini dapat meningkatkan volume pengunjung ke tempat wisata Bukit Bakukung dan meningkatkan kesejahteraan masyarakat cianten serta mengenalkan daerah Cianten yang kaya akan sumber daya alamnya kepada masyarakat luas dan menimbulkan kesadaran terhadap masyarakat akan pentingnya menjaga alam.
\end{abstract}

Kata Kunci : Kampung Wisata, Daya Tarik, Fluktuasi

\section{PENDAHULUAN}

\section{Latar Belakang}

Kuliah Kerja Nyata (KKN) Tematik Terintegrasi Universitas Ibn Khaldun merupakan program implementasi salah satu rangkaian Tri Dharma perguruan tinggi yaitu pengabdian masyarakat. Program KKN diharapkan menjadi suatu pengalaman belajar yang baru untuk menambah pengetahuan, kemampuan, dan kesadaran hidup bermasyarakat. Penempatan mahasiswa di luar kampus diharapkan dapat dimanfaatkan untuk bisa bersosialisasi, membantu dan mendampingi masyarakat memanfaatkan potensi sumber daya alam lokal dan sumber daya manusia yang ada untuk mengatasi permasalahan masyarakat dalam kurun waktu tertentu. Disamping itu mahasiswa juga diharapkan mempu memberikan motivasi dan inovasi dalam bidang pembangunan.

Kampung Wisata Cianten berdiri sejak tahun 2017 masyarakat sekitar biasa menyebut tempat itu "Bukit Bakukung" yang mana asal mula bukit itu hanya menjadi sebuah jebakan untuk hewanhewan liar yang ada di sekitar perkebunan teh cianten. Namun sejak tahun 2017 
masyarakat cianten mulai berinisiatif untuk menciptakan destinasi wisata dengan melestarikan lingkungan dan menyalurkan kreativitas masyarakat dalam menjadikan tempat wisata yang sangat menarik.

Wisata Bakukung terdapat di Kampung Pel. Cianten tepat di Rw 11 Desa Purasari Kec. Leuwiliang Kab. Bogor. Tempat wisata Bakukung masih sangat asri, sejuk. Dan wiasata Bakukung ini memanfaatkan keindahan alam pada Kampung Cianten, wisata Bakukung dibuat dengan inovasi masyarakat setempat secara gotong royong untuk kesejahteraan masyarakat itu sendiri.

Wisata Bakukung adalah Wisata yang sangat indah, namun setelah kami melakukan observasi ketempat wisata Bakukung terlihat pengunjung tetapi masih sedikit dan setelah kami melakukan wawancara dengan Ketua pengelola tempat wisata bapak Suhalim mengatakan "pengunjung sangat minim pada hari-hari biasa (senin-jum'at), pada hari-hari libur (sabtu-minggu) pengunjung sedikit ada peningkatan, dan bapak Suhalim mengatakan bahwa tempat wisata Bakukung ini tidak banyak yang mengetahui keberadaannya, karena di daerah Cianten itu tidak terdapat akses internet yang mengakibatkan sulitnya mempromosikan wisata Bakukung tersebut".

Berdasasrkan permasalahan tersebut, kami mahasiswa KKN Tematik Terintegrasi 2018 Universitas Ibn Khaldun Bogor kelompok 60 membuat informasi tentang wisata Bakukung dengan cara membuat sepanduk untuk penunjuk arah pada tempat wisata, kamipun mempromosikan wisata tersebut melalui media online seperti instagram dan youtube.

\section{Kondisi Wilayah}

Gambaran Umum Masyarakat Sasaran

- Luas Daerah : 632,120 Ha

Lahan Rumah dan pekarangan: 37,500 Ha

Lahan Sawah dan Darat

: $264,740 \mathrm{Ha}$

Lahan Perkebunan dan Negara: 326,330 $\mathrm{Ha}$

Lahan Perkantoran

: 3,550 Ha

- Batas Administrasi

Sebelah Utara : Desa Karyasari

Sebelah Timur : Desa Cibitung Wetan

Kecamatan Pamijahan

Sebelah Barat : Kabupaten Sukabumi

Sebelah Selatan : Desa Purased

- Dibidang pendidikan penduduk desa purasari Kecamatan Leuwiliang Kabupaten Bogor yaitu :

$\begin{array}{ll}\text { Belum Sekolah } & : \text { 818 Jiwa } \\ \text { Tidak Tamat SD/Sederajat } & : \text { 576 Jiwa } \\ \text { SD/Sederajat } & : 1.766 \text { Jiwa } \\ \text { SLTP/Sederajat } & : 768 \text { Jiwa } \\ \text { SLTA/Sederajat } & : 819 \text { Jiwa } \\ \text { Akademi/Diploma } & : 98 \text { Jiwa } \\ \text { Universitas (S1, S2) } & : 101 \text { Jiwa }\end{array}$

Dari data diatas masih banyak warga masyarakat yang belum mengenyam pendidikan bahkan tidak tamat SD, dari data tersebut ditemukan bahwa banyak juga warga masyarakat yang belum mampu membaca atau disebut buta aksara. Maka perlu perbaikan untuk mengatasi masalah ini melalui program buta aksara khususnya yang bersifat pragmatis dan mampu meningkatkan penghasilan melalui kewiraushaan.

\section{METODE PENGABDIAN}

Program kerja pengembangan daya tarik wisata melalui perancangan petunjuk arah berbasis media online yang akan diselenggarakan di Kampung Pel. Cianten RW 11 Desa Purasari Kec. Leuwiliang 
Kab. Bogor. adapun metode dan tahap pelaksanaan kegiatan yang akan dilaksanakan diantaranya :

Pelaksanaan pengabdian dilakukan dengan empat tahapan, dimana tahap pertama merupakan tahap observasi. Pada tahap ini kelompok pengabdi melakukan survei pendahuluan untuk melihat kondisi dilapangan mengenai wisata. Tahap kedua merupakan tahap wawancara, pada tahap ini kelompok pengabdi melakukan wawancara kepada Bapak Suhalim sebagai Ketua Pengelola Wisata Bakukung untuk mengetahui permasalahan yang terdapat di wisata Bakukung. Tahap ketiga merupakan tahap persiapan, pada tahap ini kelompok pengabdi melakukan survei untuk melihat kondisi dilapangan mengenai permasalahan yang didapat. Tahap keempat merupakan tahap pelaksanaan kegiatan, pada tahap ini kelompok pengabdi melakukan kegiatan pembuatan spanduk petunjuk arah untuk menuju tempat wisata Bakukung yang ada di Kampung Cianten dan kamipun membuat akun sosial media untuk mempromosikan Kampung Wisata Bakukung.

\section{REALISASI PROGRAM}

\section{Anggaran Biaya}

\begin{tabular}{|c|l|c|}
\hline No & \multicolumn{1}{|c|}{ Keterangan } & Jumlah \\
\hline 1. & Saldo & Rp 9.808.000 \\
\hline 2. & Biaya Konsumsi & Rp 2.916.000 \\
\hline 3. & $\begin{array}{l}\text { Biaya Kegiatan } \\
\text { KKN Rp 2.538.000 }\end{array}$ \\
\hline 4 & $\begin{array}{l}\text { Biaya Kegiatan } \\
\text { Perpisahan }\end{array}$ & Rp 4.207.000 \\
\hline 5. & Biaya Lain- Lain & Rp 147.000 \\
\hline
\end{tabular}

\section{Jadwal Kegiatan}

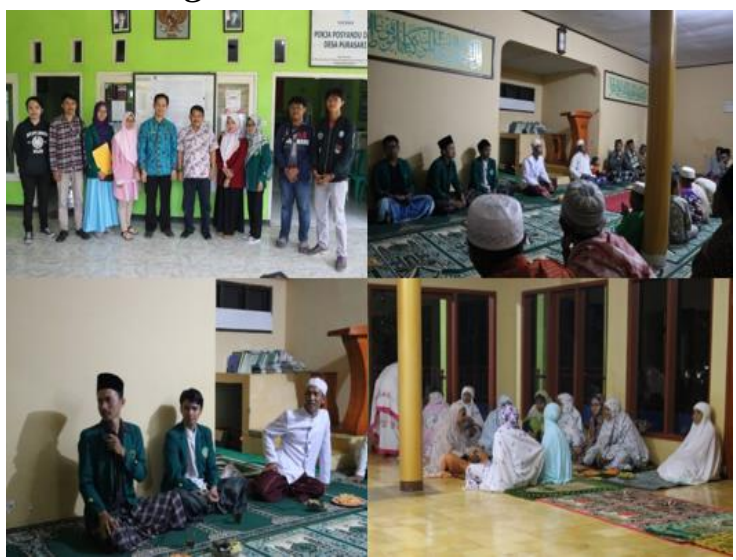

1. Kegiatan Lokakarya ( $\mathrm{Tgl} 7$ Agustus 2018 )

Lokakarya adalah pertemuan dimana kami melakukan pertemuan dengan kepala Desa Purasasri dan tokoh-tokoh masyarakat di Kampung Pel. Cianten. Kami memperkenalkan kelompok kami lalu menjelaskan tujuan kedatangan kami kepada tokoh-tokoh masyarakat yang ada disana.

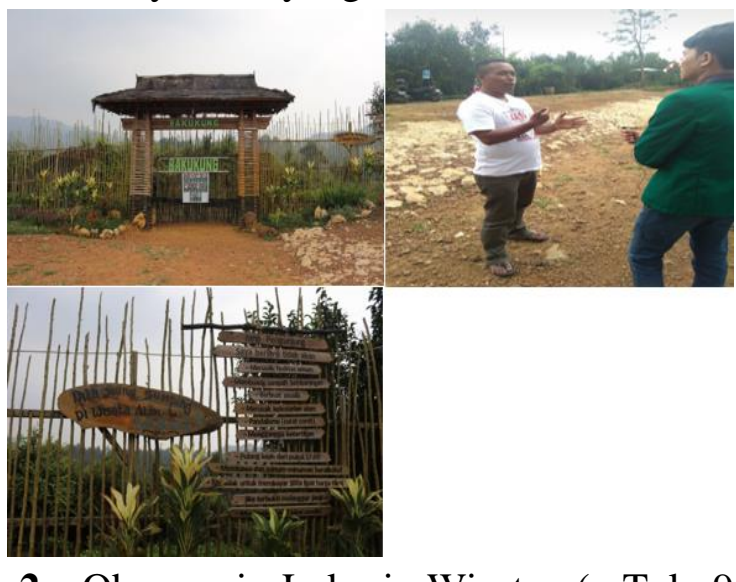

2. Observasi Lokasi Wisata ( Tgl 9 Agustus 2018 )

Observasi lokasi wisata kami lakukan untuk mengetahui kondisi yang ada di tempat Wisata. Kami melakukan wawancara dengan ketua pengelola wisata bakukung, kamipun memberikan saran untuk membuat plang tempat wisata. 


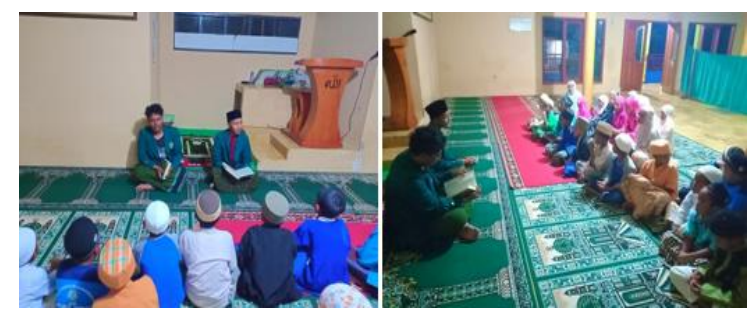

3. Cianten Mengaji Sejak Dini ( Tgl 11 Agustus 2018)

Kami mengajar ngaji dimesjid An-Nur mengajarkan anak-anak ngaji tentang Tajwid, Hafalan juz Amma, dan Iqra.

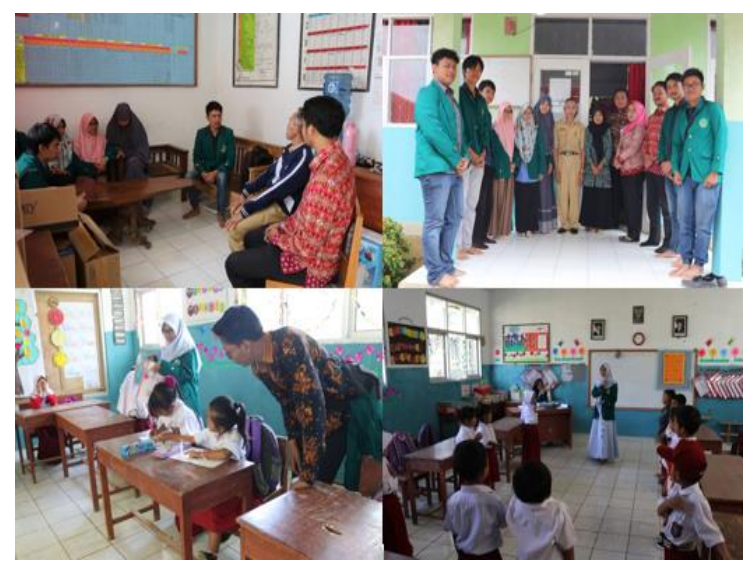

4. Mengajar SD ( Tgl 13 Agustus 2018 )

Meminta izin kepihak sekolah untuk melakukan kegiatan belajar mengajar di sekolah dasar 02 cianten. Dan melakukan kegiatan mengajar di SD tersebut. Kami mengajar pelajaran PAI. Disore hari kami mengajar Bahasa Arab.

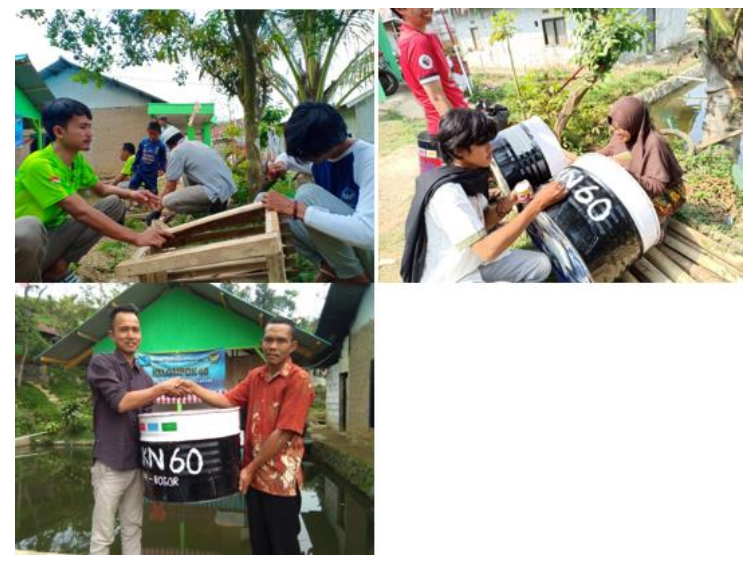

5. Pembuatan Tong Sampah ( Tgl 14 Agustus 2018)

Membuat tong sampah dengan menggunakan bambu yang mana kami memanfaatkan sumber daya alam yang ada di kampung cianten. Dan kamipun membeli tong agar warga mudah dalam pembakaran sampah.

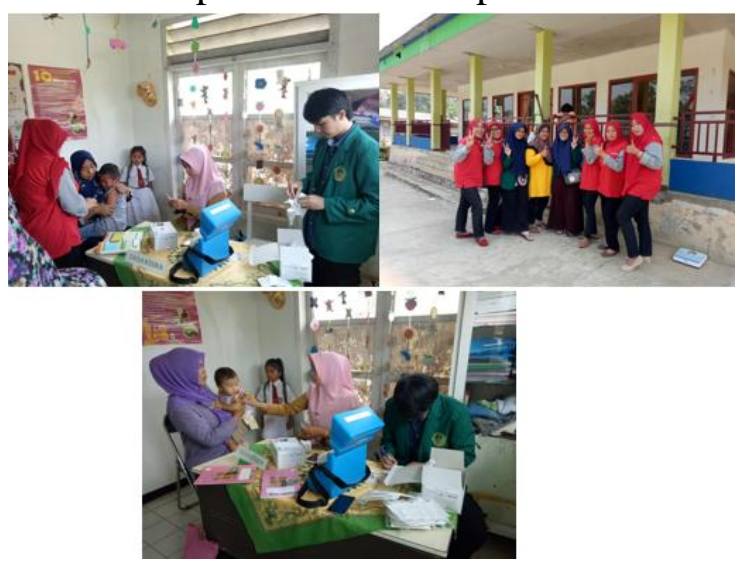

6. Posyandu, Imunisasi dan Penimbangan ( Tgl 15 Agustus 2018 ) Membantu kegiatan posyandu berupa imunisasi dan membantu penimbangan juga pemberian Vit A kepada balita di sekitar kampung Cianten.

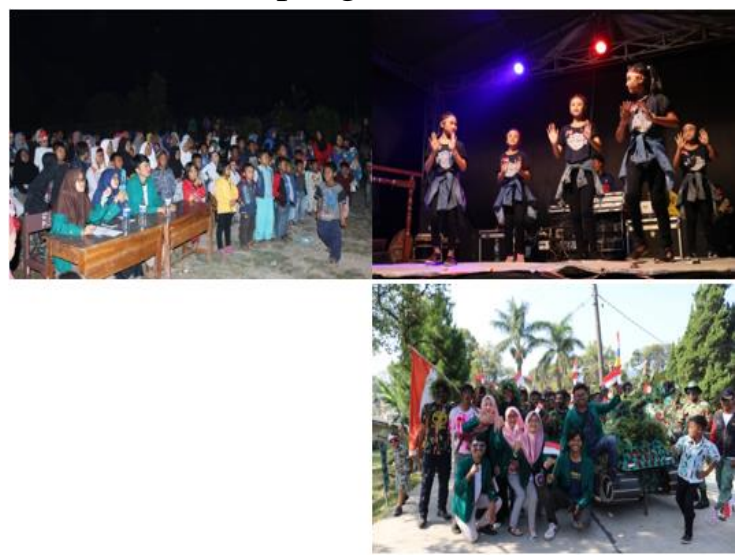

7. Panitia Karnaval 17 Agustus dan Juri Lomba

Menjadi juri di dalam acara perlombaan menari dan qosidah, mengikuti upacara dan pembuatan maskot karnaval anatar RW di kp Cianten. 


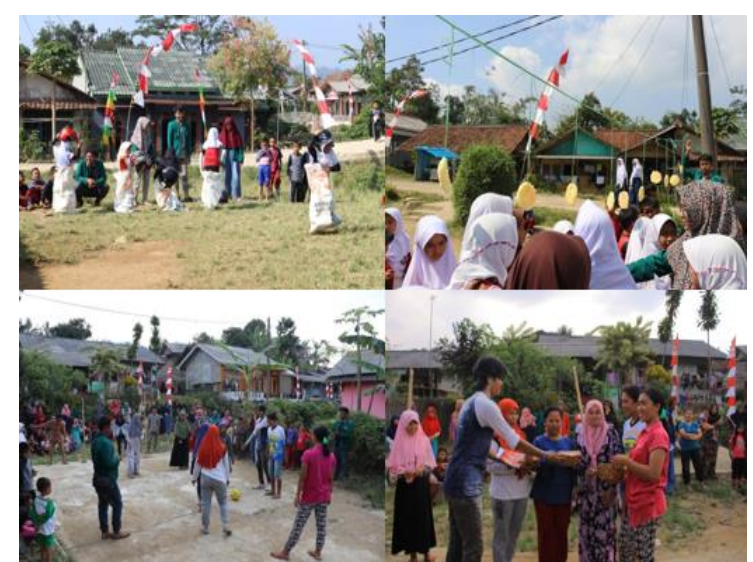

8. Perlombaan 17an ( Tgl 20 Agustus 2018 )

Perlombaan yang kami adakan yaitu untuk anak-anak SD dan Ibu-Ibu, perlombaan yang kami adakan untuk anak- anak diantaranya : lomba balap karung, lomba makan kerupuk, lomba memasukan pensil kedalam botol, lomba kelereng, lomba menendang bola, dan lomba untuk ibu-ibu diantaranya: lomba tarik tambang, lomba balap karung, lomba makan kerupuk, lomba maen bola.

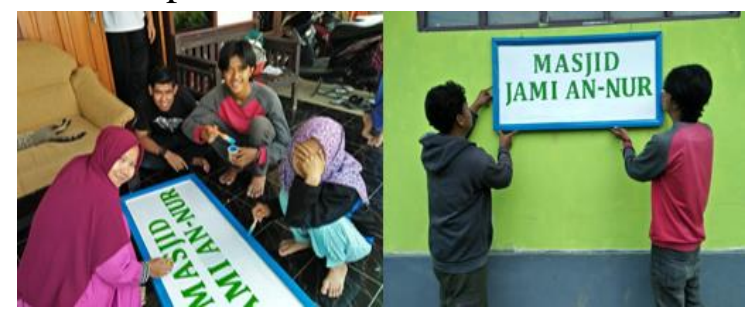

9. Tgl 25 Agustus 2018 Pembuatan Plang Mesjid

Memperindah mesjid dengan membuatkan plang mesjid dan mengecatnya dengan warna yang menarik.

10. Tgl 26 Agustus 2018 kreativitas kerajinan tangan

Memberikan peluang anak untuk mengembangkan kreativitasnya kerajinan tangan dalam membuat tempat pensil dari kain planel.

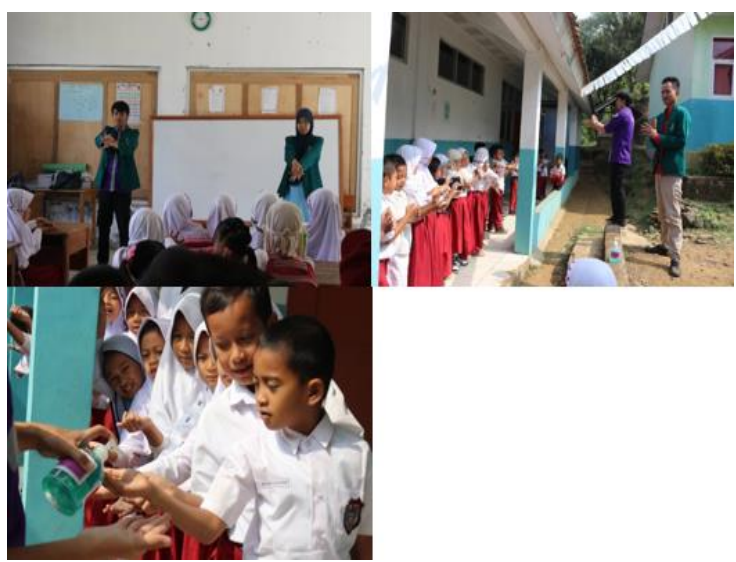

11. Penyuluhan Tujuh Langkah Mencuci Tangan ( Tgl 28 Agustus 2018 )

Penyuluhan kesehatan dengan anakanak SD dalam rangka memberitahu tata cara mencuci tangan dengan baik dan bener. Menurut Eska dalam Jurnal Abdi Dosen Pemberdayaan kesehatan merupakan kegiatan penambahan pengetahuan yang diperuntukan bagi masyarakat melalui penyebaran pesan.

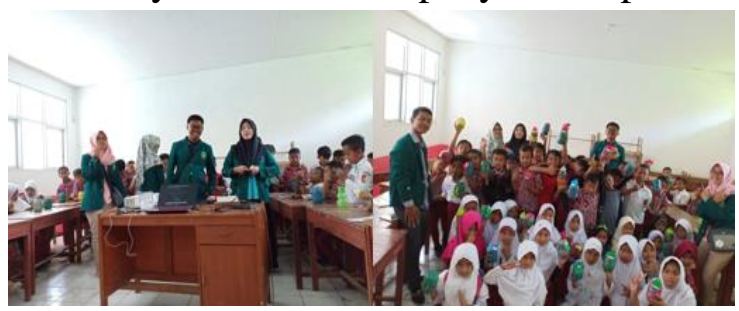

12. Penyuluhan Ekonomi, Menabung Sejak Dini (Tgl 30 Agustus 2018)

Mensosialisasikan manfaat menabung sejak dini memberikan informasi nasihat agar anak anak dapat menabung di usianya dan membagikan celengan kepada semua anak-anak. 


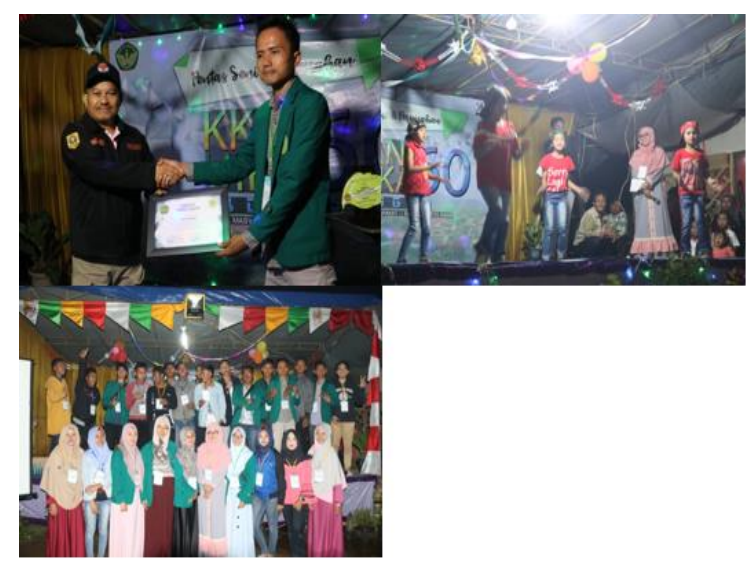

13. Pentas Seni dan Perpisahan ( Tgl 31 Agustus 2018 )

Pentas seni dan perpisahan dimana kita melakukan kegiatan pentas seni untuk anak anak dan para pemuda pemudi yang ada di kp. Pel cianten kami mengadakan lomba sebelumnya dan adapun acara mengenai perpisahan kami melibatkan tokoh dan pemuda-pemudi kp.pel-cianten sebagai panitia penyelenggara dan hasilnya sangat meriah dan terkenang.

\section{KESIMPULAN}

\section{Tujuan}

Adapun tujuan dari pelaksanaan program pengabdian masyarakat ini adalah:

a. Membantu masyarakat dalam mempromosikan tempat Wisata yang ada di kampung Pel. Cianten dengan petunjuk jalan dan menyebarkan informasi melalui media online.

b. Membantu kegiatan belajar mengajar di Mesjid An-Nur dan membantu kegiatan belajar mengajar di Sekolah Dasar, lalu mengajarkan bimbel belajar bahasa arab untuk anak-anak.

c. Membantu ibu-ibu kader dalam kegiatan posyandu tentang imunisasi, penimbangan, dan pemberian Vit A kepada balita yang ada disekitar $\mathrm{kp}$ Pel. Cianten. d. Membantu dalam kepanitian 17an menjadi juri dalam lomba menari dan lomba qosidah antar RW di kp Cianten.

e. Membuat pendekatan dengan warga masyarakat dan anak-anak dengan mengadakan perlombaan-perlombaan yang membuat masyarakat senang.

f. Membantu meningkatkan kreativitas anak-anak disana dengan mengadakan kerajinan tangan membuat tempat pensil dari kain planel.

g. Membuat plang mesjid untuk memperindah mesjid An-Nur.

h. Mengadakan penyuluhan kesehatan tentang 7 langkah mencuci tangan. Agar anak dapat mencuci tangan dengan baik dan bener.

i. Mengadakan penyuluhan ekonomi dengan tema "menabung sejak dini" membantu membuka menset anak untuk menabung sejak dini dan agar anak ingin mneyisihkan uang jajannya untuk ditabung.

j. Pensi dan perpisahan, kami mengadakan pensi untuk melihat bakat anak dan pemuda pemudi kp pel. Cianten dalam membudayakan seni yang ada disana sekaligus acara perpisahan dengan warga masyarakat kp. Pel. Cianten.

\section{Hasil Yang Diharapkan}

Dari pelaksanaan program ini diharapkan menghasilkan :

a. Peningkatan pengetahuan, sikap dan keterampilan mahasiswa sehingga memiliki kepedulian dan kemampuan untuk mengkaji, merumuskan dan memecahkan masalah-masalah kemasyarakatan yang ada di sekitar kp. Pel. Cianten

b. Terintegrasi peran perguruan tinggi, pemerintah, dan masyarakat dalam 
upaya peningkatan kesejahteraan masyarakat.

c. Dicapainya program pengembangan kampung wisata yang ada di cianten sehingga menambah kualitas kehidupan masyarakat dan meningkatkan kesadaran masyarakat untuk mengeksplor sumber daya alam yang ada.

d. Kami berharap dengan datangnya kami ke kampung Pel. Cianten dapat membantu kekurangan yang ada di kampung tersebut. Dan kami berharap dengan apa yang kami lakukan selama di kp. Pel Cianten dapat menjadikan motivasi untuk anak-anak dan warga masyarakat lainnya.

\section{SARAN}

Saran kami untuk Desa Purasari kami berharap desa dapat memperhatikan kembali kesejahteraan masyarakat kmapung pel cianten khususnya dalam hal

1. Pendidikan, dimana kurangnya motivasi belajar pada anak-anak begitupun guru yang bersangkutan kurang memberikan motivasi untuk anak-anak dalam hal pendidikan.

2. Lingkungan, kebersihan lingkungan yang kurang bersih sehingga banyak sampah dimana-mana terutama sungai yang sekarang berubah menjadi kotor.

3. Perizinan, untuk meningkatkan kesejahteraan kampung Pel. Cianten seyogyanya pemerintah dapat mempermudah perizinan lahan untuk tempat wisata.

\section{REFERENSI}

Administrasi Desa Purasari.

Eska Perdana Prasetya (2017), Pemberdayaan Masyarakat Tentang Kesehatan, Pendidikan Dan Kreatifitas, Jurnal Abdi Dosen

JURMA UIKA Thn 2018, Pendidikan Keaksarran Fungsional Berbasis Kewirausahaan dalam rangka meningkatkan IPM dan pendapatan keluarga di kabupaten Bogor. 